This is a self-archived version of an original article. This version may differ from the original in pagination and typographic details.

Author(s): Rajamäki, Sari; Mikkola, Leena

Title: Newcomers in the Workplace

Year: 2020

Version: Accepted version (Final draft)

Copyright: (c) 2020 Taylor \& Francis

Rights: In Copyright

Rights url: http://rightsstatements.org/page/lnC/1.0/?language=en

Please cite the original version:

Rajamäki, S., \& Mikkola, L. (2020). Newcomers in the Workplace. In L. Mikkola, \& M. Valo (Eds.), Workplace Communication (pp. 69-82). Routledge. https://doi.org/10.4324/9780429196881-6 


\title{
6 NEWCOMERS IN THE WORKPLACE
}

\author{
Sari Rajamäki \\ orcid.org/0000-0003-2434-6287 \\ Leena Mikkola \\ orcid.org/0000-0003-0097-975X
}

\begin{abstract}
When newcomers enter a workplace, the focus is usually only on orientation and onboarding tactics, which aim to socialize newcomers into the workplace. However, it is through workplace relationships that newcomers make sense of their work tasks and create an understanding of "our workplace". This chapter describes the processes of interpersonal communication in the workplace during a newcomer's entry phase. Newcomers may face uncertainty regarding professional performance, relationships, job tasks, or membership. This uncertainty is managed by information-seeking strategies. In social interaction with others, newcomers construct their belonging through membership negotiation and identification. Leaders and coworkers are significant parts of a newcomer's entry, but mentoring relationships can play a supporting role. A newcomer's entry is a reciprocal process in which the newcomer and other employees cocreate meanings in order to identify themselves in the context of the workplace and define their role in workplace interactions.
\end{abstract}

Keywords: identification, membership, newcomer, uncertainty management, working life, workplace communication 


\section{Introduction}

Over the course of a work career, an employee may enter many different workplaces in different organizations as well as join different teams and projects within the same organization. Along with the job itself, workplace communication and the employee's ability to fulfill their professional goals are valued (Myers \& Sadaghiani 2010). The actual job is not the only reason for remaining in or leaving a workplace. Therefore, it is crucial for workplaces to create longer-lasting connections in order to keep their employees (Elkins 2018) and to support newcomers' job satisfaction in order to lower the frequency of turnover (Bauer et al. 2007). This has changed workplaces and complicated the communication processes associated with the entry of newcomers.

From the perspective of the organization, entry is an assimilation process in which the newcomer is socialized into the organization. Socialization begins during recruitment, when the newcomer starts to build an understanding of the workplace; it continues when the newcomer becomes familiar with the workplace; finally, it goes through a metamorphosis phase, when the newcomer starts to work more actively and achieves an understanding of roles and work tasks (Jablin 1987). Because a new employee is always an investment, many types of orientation programs and onboarding tactics have been developed to facilitate newcomers' assimilation by engaging them through formal and informal policies and practices (Klein \& Polin 2012). However, in terms of communication, the entry phase can be characterized as comprising of many interaction processes that aim to achieve newcomers' identification with their new work community.

From the beginning, a newcomer actively makes sense of the workplace's social environment in order to understand how to fit in and how to define their role. Becoming a member of a workplace involves the interpersonal connections through which members organize and complete their work tasks (Myers 2010). Newcomers create an understanding of 
"our workplace" by interpreting their work tasks, professional identity, relationships, and the organization; they do so by making sense of these aspects of working life in communication situations (Tornes \& Kramer 2015). Moreover, the social construction of the workplace is rearranged during entry, when the newcomer joins the network of workplace relationships and establishes their role in workplace interactions. The aim of this chapter is to explain the salient interpersonal processes that characterize a newcomer's entry by analyzing existing knowledge about uncertainty and emotion management, relationship building, membership negotiation, and identification. The chapter focuses on how the dynamic processes of interpersonal relationships and broaden the understanding of workplace communication during the entry of newcomers.

\section{Uncertainty and emotion management in workplace interaction}

When applying for a position at a new workplace, an employee already starts to acquire information about the organization and the upcoming work tasks. The pre-entry process gives rise to newcomers' perceptions of the workplace; newcomers do not start from zero knowledge about the organization (Stephens \& Dailey 2012). When a newcomer enters the workplace, the earlier information begins to transform into knowledge through experiences in workplace interactions with others.

\section{Managing Uncertainty}

During entry, a newcomer experiences uncertainty, due to the lack of information needed to anticipate the forthcoming communication situations at work (Kramer 2004). Managing uncertainty is a natural part of interaction. A newcomer experiences uncertainty regarding 
both work responsibilities and workplace interactions, all while performing the new job and making sense of their role. Newcomers' uncertainty is also related to the organization and workplace relationships. According to Kramer (2010), newcomers experience several forms of uncertainty:

- task-related uncertainty (e.g., how to do the work);

- relational uncertainty (e.g., with whom to create relationships);

- $\quad$ organizational uncertainty (e.g., how to behave according to workplace norms);

- political or power-related uncertainty (e.g., who possesses influence and power in a workplace).

Depending on the kind of uncertainty a newcomer experiences, it affects their uncertaintymanagement and information-seeking strategies.

A newcomer's uncertainty is managed through the information provided by official orientation programs, but the most important sources of workplace information are leaders and peer coworkers (Kramer \& Sias 2014). Information is sought in different ways. A newcomer may adopt active or passive information-seeking strategies: Overt or indirect questions, conversations with third parties, testing limits, disguising conversations, surveillance or observation (Miller \& Jablin 1991). When asking questions, a newcomer has to identify the appropriate tactics. In response to overt questions, information is received quickly. However, newcomers may use indirect questions to protect their face when they are unsure of their professional performance. Third parties often become a source of information when the main source, such as the leader, is unavailable. Disguising conversations contain mutual joking and self-disclosure, and the newcomer's information-seeking about the workplace is disguised as ordinary talk. When testing limits, a newcomer breaks workplace norms in one way or another in order to gain information, for example by arriving late to a meeting in order to see the others' reaction. These active information-seeking strategies may 
provide information more quickly than passive strategies, which may also facilitate more rapid attachment to the workplace (Miller \& Jablin 1991). Passive strategies, such as observations and surveillance (Miller \& Jablin 1991), may be chosen when the newcomer is constructing their perception of power structures and of organizational norms, history, and culture.

A newcomer's information-seeking decisions are affected by motivation, level of uncertainty, and the nature of the interaction situation. Motivation guides the newcomer's uncertainty management: If they can manage the experience of uncertainty, the need for information-seeking decreases (Kramer 2004). In such a situation, newcomers may manage uncertainty on their own by remembering situations in previous workplaces. Newcomers may also have competing motives: They might be motivated to seek information, but embarrassment inhibits them from requesting it (Kramer 2004). Like all employees, the newcomer has a need to make a positive impression. Impressions are managed through selfpresentation strategies intended to control the impressions created by others (Leary \& Kowalski 1990). For example, if a newcomer has faced difficulties in their previous workplace, they may see them as sensitive information and decide not to share them with their new coworkers, to avoid making a negative impression.

Encouraging newcomers to use active strategies of seeking information may serve the goals of both the organization and the newcomer. Other members should convey to newcomers that it is acceptable to ask questions. If coworkers seem constantly busy and respond to a newcomer's questions in an uninterested manner, the use of active strategies will not take root. Even though information seeking is the main strategy for uncertainty management, not all the information is beneficial (Afifi \& Burgoon, 2000). Poorly targeted, untimely given, and nonspecific information is unhelpful and may increase a newcomer's stress. Moreover, a newcomer's previous work experience and age can affect information 
seeking (De Vos \& Freese 2011). A young newcomer with no previous work experience who is entering a workplace for the first time must engage in information seeking for a longer time than a more experienced newcomer who has been in many workplaces.

\section{Managing Emotions}

In workplace communication, employees do express and share emotions. A newcomer benefits from knowing how to manage their emotions according to workplace norms. A newcomer's adjustment and conformity are constructed through emotion management, which enables both the expression and control of emotions in the workplace (Scott \& Myers 2005). It is not uncommon for a newcomer to have feelings of ambiguity. It takes time for the newcomer to sense, identify, and learn how to react to emotions (Pickering 2018). Nonetheless, in order to maintain relationships and display respect for other members, employees need to manage their emotions (Kramer \& Hess 2002). Depending on the workplace and its communication culture, the norms that govern the expression of emotions play an important role. Newcomers learn about emotion display in the workplace by observing their coworkers, and they will eventually assimilate this information as a workplace norm.

A key reason for appropriate emotion management is to maintain professionalism in workplace interactions (Kramer \& Hess 2002). Staying professional includes presenting negative emotions as neutral and maintaining an awareness of what is appropriate when expressing positive emotions in particular situations. Emotion management also requires evaluation of the consequences of expressing negative or positive emotions (Waldron 2012). Experiences of emotion affect relationship development: Those with whom a newcomer experiences reciprocal feelings of trust and positive emotions in early interaction 
situations represent potential relationships (Teboul \& Cole 2005). During entry, a newcomer learns emotion management by observing, asking questions, and participating in interaction situations, which supports the smooth development of workplace relationships.

\section{Building relationships during workplace entry}

When entering the workplace, a newcomer's workplace relationships begin to form. During entry, all the relationships are mainly informational in nature, and they lack personal commitment. The relationships play a major role in helping a newcomer make sense of their role in the workplace, which is actualized by receiving information, receiving social support, and developing job performance (see Kramer \& Miller 2014).

A leader is often the newcomer's first contact in the workplace (Kramer \& Sias 2014). Interaction situations with the leader support the newcomer's participation in the workplace, because the leader's behavior in the presence of the newcomer guides and affects the new employee's motivation to build relationships (Jia, Cheng \& Hale 2017). A highquality leader-follower relationship strengthens the new employee's commitment as well (Sluss \& Thompson 2012). When the leader offers task instructions and advice and provides access to resources, the newcomer experiences mutuality with the leader and the workplace as a whole (Sluss \& Thompson 2012). Thus, it is essential to devote effort to the leaderfollower relationship from the beginning of the newcomer's employment.

Peer coworker relationships are the newcomer's important source of information (Kramer \& Sias 2014). At first, they are mainly informal, involving information about the work and the organization, and designated by a low level of trust and selfdisclosure (Kram \& Isabella 1985). Little by little, some of these relationships start to develop into collegial peer relationships, which offers to the newcomer a possibility to share 
more information about themselves, but the focus is still mainly on work-related issues. Collegial peer relationships consist of many processes of communication, such as social support, feedback, and a certain degree of trust, and they help in the new employee's professional growth and job performance more than informal relationships do (Kram \& Isabella 1985). The quality of work-related information received from coworkers depends on the quality of the peer relationship: The better the employee knows the peer, the more value an employee attributes to the information (Sias 2005). Regarding information seeking, newcomers often turn to closer peers rather than to informal or collegial peers (Myers et al. 2018). Thus, the development of peer relationships is crucial for the newcomer's information and knowledge management.

The development of workplace relationships is affected by the newcomer's experience of similarity and reciprocation with other members of the workplace (Teboul \& Cole 2005). A newcomer's entry affects the entire workplace and its employees. It may even be challenging for other employees to accept a newcomer as part of the workplace. Newcomers may experience difficulty initiating relationships with employees who already belong to the group. These kinds of challenges should be shared reciprocally in the workplace in order to identify solutions to potential difficulties. When the leader and peer coworkers exhibit friendliness and provide information to a newcomer, the parties create a bond that enables the development of a trust-based relationship (Schaubroeck, Peng \& Hannah 2013). Communication with the leader and the coworkers enables relational identification: A feeling of oneness and belonging in these specific relationships. As a result, the newcomer experiences more loyalty, empathy, and understanding both from and toward other members (Sluss \& Ashforth 2007). Developing good interpersonal relationships strengthens the newcomer's sense of belonging (Cranmer, Goldman \& Booth-Butterfield 2017). These relationships are productive, involving recognition of the newcomer's work and the 
expression of supportive emotions (Myers \& Gailliard 2016). To enable the development of relationships, both the newcomer and other employees need to share their thoughts and experiences about work and issues related to workplace communication.

Mentoring can help newcomers gain a deeper understanding of the workplace. A mentoring relationship is constructed when the more experienced employee provides coaching, confirmation, and help to the less experienced employee in order to support their understanding of professional identity and the organization (Kram \& Isabella 1985). Communication is focused on guidance and social support, information sharing, and feedback, which flows unidirectionally from the mentor to the newcomer (Sias 2009). Newcomers are an active part of mentoring, because they choose their information-seeking strategies when talking with the mentor (Myers 1998). The mentoring relationship enables the newcomer to cope with uncertainty and gain access to social networks that can support their career development (Bokeno \& Gantt 2000). Those who engage in mentoring during the newcomer's entry are more satisfied and have a better understanding of the organization (Jablin 2001). Mentoring deepens the newcomer's overall understanding of the organization's workplace culture.

The mentoring relationship supports the newcomer's entry because it provides opportunities to discuss and share early workplace experiences, and mentoring often involves discussions of professional identity as well (Sias 2009). Both a peer coworker relationship and a leader-follower relationship can be a mentoring relationship, and it can be developed formally or informally (Kramer \& Sias 2014). Newcomers may seek an informal mentor among their peers when they need to discuss certain workplace experiences. A peer mentor with the same age or life situation can support the newcomer's entry and ease the development of interpersonal relationships at work (Omilion-Hodges \& Sugg 2019). Many workplaces arrange formally organized mentoring programs. In such programs, senior 
members are given the responsibility of guiding a newcomer. The mentor may also support the newcomer in building other workplace relationships.

\section{Newcomers' Membership Negotiations}

When joining a workplace, newcomers start to build their membership by creating relationships, roles, values, and expectations through interpersonal communication with other members (Myers 2010). This is enacted both through role negotiations and membership negotiations.

Role negotiation is focused on work tasks, and it implies the newcomer's position in the workplace as an employee (Myers \& Oetzel 2003). The role involves the expectations and requirements that are part of the job (Morrison 1995). These role expectations are guided by norms discovered through interaction, which are then modified and reproduced through negotiation (Scott \& Myers 2010). Through the roles, newcomers construct their understanding of the workplace as a community. Moreover, the roles, which are not stable as is often supposed, help new employees understand how and with whom to work. If newcomers or other members have difficulties identifying these job-related expectations, a need for role negotiation arises.

Role negotiations take place in working situations or when the newcomer is organizing their work tasks with others (Myers \& Oetzel 2003). In role negotiations, a newcomer learns about the expectations of other members and starts to compare them with their own. Through role negotiation, a newcomer gains familiarity with coworkers, begins to assimilate the organization's culture, and becomes motivated to participate. Also, the newcomer encounters opportunities to achieve competence in their job. Coworkers can be a source of information about roles, but they can also serve as role models who help a 
newcomer understand the workplace culture (Myers, Seibold \& Park 2011). Further, the newcomer has expectations regarding what it is like to work in the workplace, but at the same time, the workplace has its own expectations for the newcomer. These experiences lead to a compromise between the newcomer's and the organization's expectations (Myers \& Oetzel 2003).

Membership negotiation is a communication process through which the newcomer becomes a member of a workplace's social network (Scott \& Myers 2010). During workplace entry, role negotiation lays the groundwork for membership negotiations (Myers 2010). Membership negotiation is one of the basic processes of organizational constitution (McPhee \& Zaug 2009). Thus, membership negotiations reconstruct the workplace.

Membership negotiation is a reciprocal process in which the newcomer starts to develop interpersonal relationships with coworkers. This happens through mutual acceptance and social judgments that consist of the newcomer's assessments of coworkers and coworkers' assessments of them (Myers 2010). It is natural for a newcomer to seek interesting and professionally attractive coworkers, and at the same time, coworkers analyze what the newcomer has to offer them. For example, during the first days at work, a newcomer may already be assigned responsibility for a project. A coworker may have had experience with the same work task and may consequently want to share it with the newcomer. The newcomer and their coworker then need to negotiate both their work tasks and their relationship, and at the same time, modify their membership in the project.

In membership negotiations, the new employee's personal and professional expectations are balanced in interactions with other members. In interpersonal communication, newcomers actively produce their own membership, and the meanings of the membership are created and re-created over time (Scott \& Myers 2010). This occurs through adapting and individualizing relational and work-related information received from other 
members in formal and informal communication (Scott \& Myers 2010). For example, a coworker's encouragement to participate in lunch discussions in a group can help the newcomer experience themselves as a member.

Even though a newcomer pursues membership negotiations to achieve acceptance as a workplace member, receiving acceptance from other members cannot be taken for granted (Scott \& Myers 2005). Nonacceptance from coworkers or conflicts in relationships can result in experiences of nonbelonging or exclusion, which is why relationship building should be supported in workplace long after the first few weeks of the newcomer's entry (Nifadkar \& Bauer 2016). If the newcomer actively tries to make contact with other members and share ideas with them but they do not take newcomer's ideas into account, it may affect the newcomer's ability to develop a sense of membership. Therefore, the experience of familiarity with other members can facilitate the newcomer's participation in all kinds of situations, such as those involving problem-solving and decision-making (Myers \& Oetzel 2003).

Membership negotiations continue as the employee's career proceeds over time. This may sometimes give rise to the experience of role confusion, for example because of a change in their title and in their roles as well as in the roles of their coworkers (Dailey 2016). If the newcomer's expectations regarding workplace relationships differ significantly from the workplace's culture, this incongruity may complicate membership negotiations or delay identification. At their best, however, membership negotiations support newcomers' identification with the workplace because they help to resolve the tension between the newcomer's needs and the collective interests of the workplace (Scot \& Myers 2010).

\section{Newcomers' Organizational Identification}


An employee's participation in work is connected to high levels of organizational identification and low levels of intent to leave (Atouba 2018). Hence, how newcomers identify themselves in the workplace community is crucial. Organizational identification is an employee's experience of oneness with other members of an organization - or with the workplace itself - and it encourages employees to define themselves in terms of membership (Mael \& Ashforth 1992). Identification is a dynamic process. The newcomer's identity starts to alter and linkages between people and groups are formed. New employees may have many groups, tasks, and situations in which their process of identifying themselves can vary across time. (Scott, Corman \& Cheney 1998.) In general, it is easier for employees to identify themselves first as a part of a smaller group and through that as a part of the organization (Silva \& Sias 2010).

The construction of identification begins as early as recruitment, and a potential future employee reflects on their suitability for a workplace when they hear about the vacancy (Stephens \& Dailey 2012). Employees' personal experiences with the organization before entry influence their identification. However, identification is principally constructed in workplace communication. How coworkers speak about their workplace is significant. In addition, both leaders and peer coworkers can express their appreciation of the newcomer's membership to support the identification. The development of identification during entry affects the employee's later experiences in a workplace (Zhu, Tatachari \& Chattopadhyay 2017).

Feedback and social support from coworkers supports both professional and team identification (Horstmeier et al. 2016). However, identification may differ in different situations in the workplace (Scott \& Stephens 2009). An employee can identify themselves in many ways: for example, in terms of their profession when talking about work tasks, and in terms of their team membership when talking about team goals. 
Identification can also be constructed through technology-mediated communication. Employees who are not physically in the same place can share their thoughts and learn about their workplace, which facilitates the development of identification (Cheney, Christensen \& Dailey 2014). To support the strengthening of identification, leaders can provide opportunities for newcomers to receive feedback and social support on enterprise social media platforms, for example (Sharma \& Bhatnagar 2016). Such opportunities - either technology-mediated or face-to-face - make newcomers feel valued and included.

Newcomers can also be supported by enabling social interaction, creating a positive work climate, and including feedback discussions in team meetings (Horstmeier et al. 2016).

Relational identification means that an employee starts to define themselves in terms of a given role relationship, such as the follower in a leader-follower relationship or a partner in a coworker relationship (Sluss \& Ashforth 2007). Relational identification includes both role-based and personal identities. It differs from organizational identification because it is constructed in specific relationships that are affected by particular roles and expectations, such as interpersonal attraction (Sluss \& Ashforth 2007). Role-relationship development also requires perceived similarity and positive affect (Miller 2002). When thinking of their peer coworker relationships, newcomers often reflect on with whom they identify themselves and what kind of a coworker they would like to be for others.

Relational identification supports entry, but ambivalence may arise as well. For example, a newcomer may believe a peer coworker is thoughtfully providing information about communication technology used at the workplace but also perceive that the same coworker behaves with insufficient professionalism when working with others. This kind of incongruity may lead to ambivalent relational identification (Sluss \& Ashforth 2007). Especially in the initial phase of entry, when newcomers are uncertain about their roles and relationships, overidentification may occur (Ashforth 2001). Newcomers may experience 
pressure related to how to do the new work, and they may feel the need to do their best to ensure that their coworkers appreciate them as a professional but also as a coworker. In such a situation, a newcomer may pretend to have qualities they factually lack, or they may withhold their real opinion if it differs significantly from a coworker's in order to maintain face (Kramer 2004). Identification is constructed in the context of relationships, and it may vary and be complex. However, successful identification is important both for workplace productivity and the new employee's experience.

\section{Practical Implications}

All workplaces are unique social systems in which individual members create and share meanings. To support the entry of newcomers, they should be encouraged to participate in workplace interactions from the beginning to create a sense of acceptance. The newcomer should also be encouraged to use active information-seeking strategies to manage uncertainty, as the use of active strategies eases their entry. Coworkers should be aware of the needs related to uncertainty management, and they should invite the newcomers to talk about their concerns.

Newcomers' and other employees' expectations regarding the development of interpersonal relationships may vary. Not all newcomers seek the same kind of membership or identification, and to a certain degree, everyone has a right to decide how they belong. The leader and peer coworkers could ask the newcomer to outline their expectations, interests, and motivations regarding the workplace in order to identify the kinds of interaction that would promote the newcomer's sense of belonging.

If the workplace has many new temporary project employees, how should they be included in the workplace? They may not have possibilities or even willingness to develop 
close relationships, but they still need to create task-oriented relationships with others to successfully manage the project. The leader of the project can facilitate engagement and identification by reflecting on and talking about the communication practices of the workplace with employees.

Both newcomers and other employees need to actively participate in interaction situations in order to enable reciprocal communication. If the workplace is large, the leader of the department or the team can encourage other members to mentor, share information with, and provide social support to the newcomer. Social support is indeed significant for newcomers, and they therefore need to establish coworker relationships. This produces a kind of paradox because the newcomer has a strong need for social support during entry, when uncertainty is high, but at this point all their relationships are by definition only in their initial stages. Therefore, it matters how other employees behave toward newcomers in early interaction situations.

When a newcomer enters the workplace, workplace communication is affected too. It is reasonable to question and evaluate communication practices, and the other members can encourage the newcomer to take part in developing these practices. A newcomer usually has a fresh perspective to observe their new workplace's practices, and the joint goal can be the developing of the organization's communication culture.

The entry of a newcomer is, after all, an unpredictable and situational process. In some cases, information seeking, mentoring, and relationship development cannot guarantee successful identification. Newcomers may find it challenging to identify themselves as members. The entirety of the workplace is significant in terms of supporting the entry of newcomers. Understanding the interpersonal processes, such as uncertainty management, membership negotiation, and different ways to engage in workplace 
relationships, can enable both newcomers and the workplace as a whole to adapt to different expectations and create a shared understanding.

What to Consider in the Workplace:

- The entry of newcomers into the workplace is a reciprocal process. Both the newcomer and other members participate in membership negotiations in which employees create an understanding of the membership on the basis of mutual interactions.

- Workplaces should recognize the challenges newcomers and other members may face during entry, such as experiences of uncertainty, from the perspective of both the newcomer and the others. It then becomes possible to support employees by open talk.

- Newcomers need to be aware of their previous experiences of and expectations about workplace relationships, but they should also reflect on and share their thoughts with other members. Newcomers should remember to be active and ask questions instead of only observing other members in the workplace.

- It is through interpersonal relationships that newcomers identify themselves as participants in the workplace. A mentor, leader, or coworker should devote time to the development of relationships and actively make contact with the newcomer. Getting to know coworkers will facilitate a newcomer's participation and sense of membership.

- It is important to engage in mentoring to support newcomers' entry and plan ways to support the development of informal mentoring relationships. A mentor with whom newcomers can discuss and share their thoughts can encourage newcomers to develop relationships with other members. 
- Every workplace and newcomer experience is unique. Understanding the importance of different communication processes enables the construction of a flexible and confirming entry.

\section{References}

Afifi, W. A. \& Burgoon, J. K. 2000. The impact of violations on uncertainty and the consequences for attractiveness. Human Communication Research 26, 203-233.

Ashforth, B. E. 2001. Role transitions in organizational life: An identity-based perspective. Mahwah, NJ: Lawrence Erlbaum Associates.

Atouba, Y. C. 2018. Tackling the turnover challenge among IT workers: Examining the role of internal communication adequacy, employee work participation, and organizational identification. Communication Reports 31(3), 174-187.

Bauer, T. N., Bodner, T., Erdogan, B., Truxillo, D. M., \& Tucker, J. S. 2007. Newcomer adjustment during organizational socialization: A meta-analytic review of antecedents, outcomes, and methods. Journal of Applied Psychology 92(3), 707-721.

Bokeno, R. M. \& Gantt, V. W. 2000. Dialogic mentoring: Core relationships for organizational learning. Management Communication Quarterly 14(2), 237-270.

Cheney, G., Christensen, L. T., \& Dailey, S. L. 2014. Communicating identity and identification in and around organizations. In L. L. Putnam \& D. K. Mumby (Eds) The Sage handbook of organizational communication: Advances in theory, research and methods. 3rd ed. Thousand Oaks, CA: Sage, 695-716. 
Cranmer, G. A., Goldman, Z. W., \& Booth-Butterfield, M. 2017. The mediated relationship between received support and job satisfaction: An initial application of socialization resources theory. Western Journal of Communication 81(1), 64-86.

Dailey, S. L. 2016. I'm new ... again: Reconceptualizing the socialization process through rotational programs. Communication Studies 67(2), 183-208.

De Vos, A. \& Freese, C. 2011. Sensemaking during organizational entry: Changes in newcomer information seeking and the relationship with psychological contract fulfillment. Journal of Occupational and Organizational Psychology 84(2), 288-314.

Elkins, D. M. 2018. Welcome to the workplace: The shift from orientation to onboarding in the socialization of millennial newcomers. In S. A. Smith (Ed.) Recruitment, retention, and engagement of a millennial workforce. Lanham, MD: Lexington Books, 63-81.

Horstmeier, C. A. L, Homan, A. C., Rosenauer, D. \& Voelpel, S. C. 2016. Developing multiple identifications through different social interactions at work. European Journal of Work and Organizational Psychology 25(6), 928-944.

Jablin, F. M. 1987. Organizational entry, assimilation, and disengagement/exit. In F. M. Jablin \& L. L. Putnam (Eds.) Handbook of organizational communication: An interdisciplinary perspective. Newbury Park, CA: Sage, 679-740.

Jablin, F. M. 2001. Organizational entry, assimilation, and disengagement/exit. In F. M. Jablin \& L. L. Putnam (Eds.) The new handbook of organizational communication: Advances in theory, research, and methods. Thousand Oaks, CA: Sage, 679-740.

Jia, M., Cheng, J. \& Hale, C. L. 2017. Workplace emotion and communication: Supervisor nonverbal immediacy, employees' emotion experience, and their communication motives. Management Communication Quarterly 31(1), 69-87. 
Klein, H. J. \& Polin, B. 2012. Are organizations onboard with best practice onboarding? In C. Wanberg (Ed.) The Oxford handbook of socialization. New York, NY: Oxford University Press, 267-287.

Kram, K. E. \& Isabella, L. A. 1985. Mentoring alternatives: The role of peer relationships in career development. Academy of Management Journal 28(1), 110-132.

Kramer, M. W. 2004. Managing uncertainty in organizational communication. Mahwah, NJ: Lawrence Erlbaum Associates Publishers.

Kramer, M. W. 2010. Organizational socialization: Joining and leaving organizations. Cambridge: Polity.

Kramer, M. W. \& Hess, J. 2002. Communication rules for the display of emotions in organizational settings. Management Communication Quarterly 16, 66-80.

Kramer, M. W. \& Miller, V. D. 2014. Socialization and assimilation. In L. L. Putnam \& D. K. Mumby (Eds) The Sage handbook of organizational communication: Advances in theory, research and methods. 3rd ed. Thousand Oaks, CA: Sage, 525-547.

Kramer, M. W. \& Sias, P. M. 2014. Interpersonal communication in formal organizations. In C. R. Berger (Ed.) Interpersonal communication. Berlin: De Gruyter Mouton, 467-491.

Leary, M. R. \& Kowalski, R. M. 1990. Impression management: A literature review and twocomponent model. Psychological Bulletin 107, 14-47.

Mael, F. \& Ashforth, B. E. 1992. Alumni and their alma mater: A partial test of the reformulated model of organizational identification. Journal of Organizational Behavior 13(2), 103-123. 
McPhee, R. D., \& Zaug, P. 2009. The communicative constitution of organizations. In L. L. Putnam \& A. M. Nicotera (Eds.) Building theories of organization: The constitutive role of communication. New York, NY: Routledge, 21-47.

Miller, N. 2002. Personalization and the promise of contact theory. Journal of Social Issues $58,387-410$.

Miller, V. D. \& Jablin, F. M. 1991. Information seeking during organizational entry: Influences, tactics, and a model of the process. Academy of Management Review 16, 92-120.

Morrison, E. 1995. Information usefulness and acquisition during organizational encounter. Management Communication Quarterly 9(2), 131-155.

Myers, K. K. 2010. Workplace relationships and membership negotiations. In S. W. Smith \& S. R. Wilson (Eds.) New directions in interpersonal communication research. Thousand Oaks, CA: Sage, 135-156.

Myers, K. K. \& Gailliard, B. M. 2016. Organizational entry, socialization, and assimilation in health care organizations. In T. R. Harrison \& E. A. Williams (Eds.) Organizations, communication, and health. New York: Routledge, 31-48.

Myers, K. K. \& Oetzel, J. G. 2003. Exploring the dimensions of organizational assimilation: Creating and validating a measure. Communication Quarterly 51, 438-457.

Myers, K. K. \& Sadaghiani, K. 2010. Millennials in the workplace: A communication perspective on millennials' organizational relationships and performance. Journal of Business and Psychology 25, 225-238. 
Myers, K. K., Seibold, D. R., \& Park, H. S. 2011. Interpersonal communication in the workplace. In J. A. Daly \& M. L. Knapp (Eds.) Handbook of interpersonal communication. 4th ed. Thousand Oaks, CA: Sage, 527-562.

Myers, S. A. 1998. FTAs as organizational newcomers: The association between supportive communication relationships and information seeking. Western Journal of Communication $62(1), 54-73$.

Myers, S. A., Cranmer, G. A., Goldman, Z. W., Sollitto, M., Gillen, H. G., \& Ball, H. 2018. Differences in Information Seeking Among Organizational Peers: Perceptions of Appropriateness, Importance, and Frequency. International Journal of Business Communication 55(1), 30-43.

Nifadkar, S. S. \& Bauer, T. N. 2016. Breach of belongingness: Newcomer relationship conflict, information and task-related outcomes during organizational socialization. Journal of Applied Psychology 101(1), 1-13.

Omilion-Hodges, L. M. \& Sugg, C. E. 2019. Millennials' views and expectations regarding the communicative and relational behaviors of leaders: Exploring young adults' talk about work. Business and Professional Communication Quarterly 82(1), 74-100.

Pickering, K. 2018. Learning the emotion rules of communicating within a law office: An intern constructs a professional identity through emotion management. Business and Professional Communication Quarterly 81(2), 199-221.

Schaubroeck, J. M., Peng, A. C., \& Hannah, S. T. 2013. Developing trust with peers and leaders: Impacts on organizational identification and performance during entry. Academy of Management Journal 56(4), 1148-1168. 
Scott, C. R., Corman, S. R., \& Cheney, G. 1998. Development of a structurational model of identification in the organization. Communication Theory 8, 298-336.

Scott, C. R. \& Myers, K. K. 2005. The socialization of emotion: Learning emotion management at the fire station. Journal of Applied Communication Research 33(1), 67-92.

Scott, C. R. \& Myers, K. 2010. Toward an integrative theoretical perspective on organizational membership negotiations: Socialization, assimilation, and the duality of structure. Communication Theory 20(1), 79-105.

Scott, C. R. \& Stephens, K. K. 2009. It depends on who you're talking to...: Predictors and outcomes of situated measures of organizational identification. Western Journal of Communication 73, 370-394.

Sharma, A. \& Bhatnagar, J. 2016. Enterprise social media at work: Web-based solutions for employee engagement. Human Resource Management International Digest 24(7), 16-19.

Sias, P. M. 2005. Workplace relationship quality and employee information experiences. Communication Studies 56(4), 375-395.

Sias, P. M. 2009. Organizing relationships: Traditional and emerging perspectives on workplace relationships. Thousand Oaks, CA: Sage.

Silva, D. \& Sias, P. M. 2010. Connection, restructuring, and buffering: How groups link individuals and organizations. Journal of Applied Communication Research 38(2), 145-166.

Sluss, D. M. \& Ashforth, B. E. 2007. Relational identity and identification: Defining ourselves through work relationships. Academy of Management Review 32(1), 9-32. 
Sluss, D. M. \& Thompson, B. S. 2012. Socializing the newcomer: The mediating role of leader-member exchange. Organizational Behavior and Human Decision Processes 119(1), $114-125$.

Stephens, K. K. \& Dailey, S. L. 2012. Situated organizational identification in newcomers: Impacts of preentry organizational exposure. Management Communication Quarterly 26(3), $404-422$.

Teboul, J. C. B. \& Cole, T. 2005. Relationship development and workplace integration: An evolutionary perspective. Communication Theory 15, 389-413.

Tornes, M. \& Kramer, M. W. 2015. The volunteer experience in temporary organizations: Volunteer role negotiation and identification in a pop-culture convention. Communication Studies 66(5), 590-606.

Waldron, V. R. 2012. Communicating emotion at work. Cambridge: Polity Press.

Zhu, J., Tatachari, S. \& Chattopadhyay, P. 2017. Newcomer identification: Trends, antecedents, moderators, and consequences. Academy of Management Journal 60(3), 855879. 